\title{
ARIMA Model in Predicting Banking Stock Market Data
}

\author{
Mohammad Almasarweh ${ }^{1} \&$ S. AL Wadi ${ }^{2}$ \\ ${ }^{1}$ Department of Business Administration, The University of Jordan, Aqaba, Jordan \\ ${ }^{2}$ Department of Risk Management and Insurance, Faculty of Management and finance, The University of Jordan, \\ Jordan \\ Correspondence: S. AL Wadi, Department of Risk Management and Insurance, Faculty of Management and \\ finance, The University of Jordan, Jordan. E-mail: sadam_alwadi@yahoo.co.uk
}

Received: June 12, 2018 Accepted: September 20, 2018 Online Published: October 29, 2018

doi:10.5539/mas.v12n11p309 URL: https://doi.org/10.5539/mas.v12n11p309

\begin{abstract}
Banking time series forecasting gains a main rule in finance and economics which has encouraged the researchers to introduce a fit models in forecasting accuracy. In this paper, the researchers present the advantages of the autoregressive integrated moving average (ARIMA) model forecasting accuracy. Banking data from Amman stock market (ASE) in Jordan was selected as a tool to show the ability of ARIMA in forecasting banking data. Therefore, Daily data from 1993 until 2017 is used for this study. As a result this article shows that the ARIMA model has significant results for short-term prediction. Therefore, these results will be helpful for the investments.
\end{abstract}

Keywords: Short term forecasting, ARIMA model, closed time series

\section{Introduction}

Predicting is a hot topic for many kind of people since the institutions are emphasis on two ways which are decision making and strategy of the future work. Banking time series data and financial time series in general is very hard in decomposition and forecasting because the data are non-stationary and non-linear with high heteroscedasticity (Pai \& Lin, 2005; Wang et al., 2012; Wei, 2013). The next plan of the investors is to enhance their profits less risk. This idea force the researchers to develop many predicting models such as artificial neural network, hybrid models and ARIMA models for more details refer to (Atsalakis\&Kimon, 2009; Mitra, 2009). ARIMA model is a traditional model with widely application in stock market data application (Wang, 2011; Awajan et al., 2017a). This model is generated by two approaches which are statistical and artificial intelligence techniques (Wang, 2011; Awajan et al., 2017b).

ARIMA model has many applications in many fields such as: (Yunus et al., 2016) uses ARIMA models to capture time correlation and possibility distribution of determined wind-pace time collection records is offered. (Vaccaro et al., 2015) suggests ARIMA model in hybrid architecture for electricity price forecasting (Liu et al, 2015) implements ARIMA model in the software program reliability boom section.

As a critically review, many researchers have been developing predicting models such as exponential method, regression model, GARCH approaches and others. However, only some related works that has used ARIMA model in predicting stock market data for more details refer to (Meyler et al., 1998; Javier et al., 2003; Khashei et al., 2009; Khasheiet. al., 2012; Lee \& Ho, 2011; Wang, 2011). Whereas, rarely to find any article that utilize Amman Stock Exchange using ARIMA model in forecasting such as (Alwadi, 2015).

In this research the researchers implementing ARIMA model for banking stock market data then some results of forecasting are obtained. The obtained results from real data established the potential asset of ARIMA model to offer for the investors forecasting that could assistance investment decision making. This research is organized as: Section 2 presents brief overview of mathematical models used.Section3 presents the results obtained and the methodology used. Finally, in section 4 is the conclusion.

\section{Mathematical Models}

2.1 Autoregressive Integrated Moving-Average Model (ARIMA (p,d,q))

The auto-regressive moving average (ARMA) models are used in stationary stock market data only, this model 
contains three combination models which are (Box \&Henkins, 1970; Awajan et al., 2017a):

1) autoregressive (AR) model and a moving average

2) (MA) model.

3) $\left\{\mathrm{e}_{\mathrm{t}}\right\}$ : white noise $(\mathrm{WN})$ process,

A time series $\left\{Y_{t}\right\}$ is said to follow the $\operatorname{ARMA}(p, q)$ model if:

$$
\mathrm{Y}_{\mathrm{t}}=\grave{\mathrm{i}}+\phi_{1} \mathrm{Y}_{\mathrm{t}-1}+\phi_{2} \mathrm{Y}_{\mathrm{t}-2} \ldots+\phi_{\mathrm{p}} \mathrm{Y}_{\mathrm{t}-\mathrm{p}}+\mathrm{e}_{\mathrm{t}}-\grave{\mathrm{e}}_{1} \mathrm{e}_{\mathrm{t}-1}-\grave{\mathrm{e}}_{2} \mathrm{e}_{\mathrm{t}-2} \ldots-\grave{\mathrm{e}}_{\mathrm{q}} \mathrm{e}_{\mathrm{t}-\mathrm{q}}
$$

Where $\mathrm{p}$ and $\mathrm{q}$ are greater than zeros, prefers to autoregressive part (AR), q refers to moving part (MA) and $\left\{\mathrm{e}_{\mathrm{t}}\right\}$ is the white noise.

An extension of the ordinary ARMA model is the auto-regressive integrated moving-average model (ARIMA $(\mathrm{p}, \mathrm{d}, \mathrm{q}))$ given by :

$$
\phi_{\mathrm{p}}(\mathrm{B})(1-\mathrm{B})^{\mathrm{d}} \mathrm{Y}_{\mathrm{t}}=\grave{\mathrm{e}}_{0}+\grave{\mathrm{e}}_{\mathrm{q}}(\mathrm{B}) \mathrm{e}_{\mathrm{t}}
$$

Where $\mathrm{p}, \mathrm{d}$ and $\mathrm{q}$ denote orders of auto-regression, integration (differencing) and moving average, respectively. When $\mathrm{d}=0$, the ARIMA model reduces to the ordinary ARMA model

\subsection{Accuracy Criteria}

This section consists of two subsections. Firstly, we will present the criteria which have been used to make a fair comparison, and then the framework comparison will be presented with more details. The researchers have been adopted to compare the performance of the models within three types of accuracy criteria which are Mean square error (MSE), Root mean squared error (RMSE) and Mean absolute error (MAE). For more details about the mathematical model refer to (Awajan et al., 2017a; Jaber et al., 2017).

\section{Methodology, Results and Discussion}

Generally, this article is different from the other related article in literature in the application of the ARIMA model since in this research paper the best ARIMA model for banking stock market data will be implemented for forecasting. The MINTAB software is used to get the results. The daily price index of Amman Stock Exchange (ASE) for a specific period of time has been selected as the statistical population; about 2000 observations were accumulated for each variable from related databases in the mentioned period from 1993 to 2017. Figure 1 shows the diagram of the dataset.

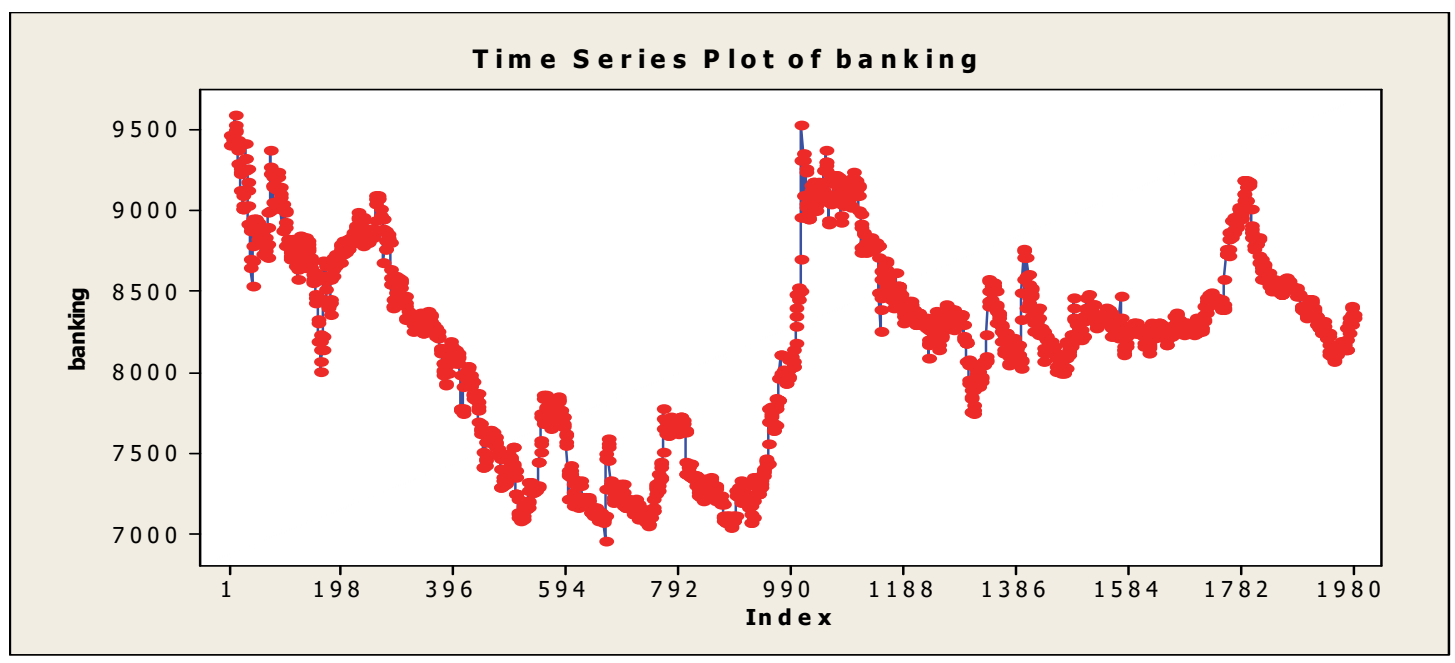

Figure 1. Diagram of the dataset

To find the fitted ARIMA model, RMSE is selected as criteria since there are many ARIMA models can be established for one column of dataset based on using different values of $p, d$ and $q$. Therefore, the fitted ARIMA model which has less RMSE. The following Table will show all the possible fitted ARIMA models with its RMSE. 
Table 1. All possible of ARIMA models with its RMSE

\begin{tabular}{|c|c|c|c|c|c|c|}
\hline ARIMA & RMSE & ARIMA & RMSE & ARIMA & & RMSE \\
\hline$\left(\begin{array}{lll}0 & , 0 & , 0\end{array}\right)$ & Not fitted & $\left(\begin{array}{lll}0 & , 2 & , 0\end{array}\right)$ & Not fitted & $(1,1$ & ,2) & 1.4 \\
\hline$\left(\begin{array}{lll}0 & , 0 & , 1\end{array}\right)$ & 2.1 & $\left(\begin{array}{lll}0 & , 2\end{array}\right)$ & 2.7 & $(1,2$ & ,0) & Not fitted \\
\hline$\left(\begin{array}{lll}0 & , 0 & , 2\end{array}\right)$ & 2.2 & $\left(\begin{array}{lll}1 & , 0 & , 0\end{array}\right)$ & Not fitted & $(1,2$ & ,1) & 3.00 \\
\hline$, 1 \quad, 0)$ & Not fitted & $\left(\begin{array}{lll}1 & , 0 & , 1\end{array}\right)$ & 2.6 & $(1,2$ & ,2) & 3.1 \\
\hline$, 2,0)$ & Not fitted & $\left(\begin{array}{lll}1 & , 0 & , 2\end{array}\right)$ & 2.09 & $(2$ & $, 0)$ & Not fitted \\
\hline$\left(\begin{array}{lll}0 & , 1 & , 1\end{array}\right)$ & 1.9 & $(1,1,0)$ & Not fitted & $(2$ & ,1) & 1.9 \\
\hline$, 1,2)$ & 1.7 & $(1,1,1)$ & 1.6 & $(2,0$ & ,2) & 2.1 \\
\hline$, 1 \quad, 0)$ & Not fitted & $, 1 \quad, 2)$ & 2.09 & $(2$ & ,1) & 1.5 \\
\hline$, 1 \quad, 1)$ & 2.00 & $, 2,0)$ & Not fitted & $(2$ & ,2) & 1.56 \\
\hline
\end{tabular}

Based on Table 1,researchers noted that:

1) The values of $p, d$ and $q$ are between 0 and 2 only since these values impossible to be in the minus also theses values should not be more than 2 since the estimation of the parameters will be worthless.

2) RMSE is varied between 4.00 and 5.00 based on the dataset used. Therefore, After the dataset is implemented using the software then ARIMA $(1,1,2)$ was found the best with RMSE $=1.4$.

3) In some cases ARIMA model is not fitted which means that the estimation of the dataset cannot be done then it should be ignored.

\section{Conclusion}

This paper showed a new model that delivers short-term predicting of the new high technology procedure. After collecting sufficient real data to construct a stock market data, an ARIMA model are implemented over the dataset performed to improve short-term prediction. Application of the method in the case of banking stock market data verified its accuracy and demonstrated its presentation capabilities. Around 200 observations were collected to implement the forecasts of this and the best ARIMA model was selected based on the most famous criteria which is MSE. Another important observation is that the forecasting accuracy of the ARIMA model diminishes gradually at this stage of the growth process, from period to period. This method can be applied and suitable for cases of the high-technology market especially for the banks since it gives a significant indicator for the future. The method was limited to a short term forecasting and it is not useful for long term. Future research in this topic includes other forecast horizons stock market data such as industrial data.

\section{References}

Alwadi, R. (2015). Forecasting short term financial data. European Scientific Journal, 11(25), 251-255.

Atsalakis G. S., \& Kimon, P. V. (2009). Forecasting stock market short-term trends using a neuro-fuzzy methodology. Expert Systems with Applications, 36(7), 10696-10707.

Awajan, A. M., Ismail, M. T., \& Al Wadi, S. (2017a). A hybrid EMD-MA for forecasting stock market index. Italian Journal of Pure and Applied Mathematics, 38(1), 1-20.

Awajan, A. M., Ismail, M. T., \& Wadi, S. A. (2017b). Forecasting time series using EMD-HW bagging. International Journal of Statistics \& Economics ${ }^{\mathrm{TM}}$, 18(3), 9-21.

Box, G. E. P., \& Jenkins, G. M. (1970). Time series analysis: Forecasting and control. San Francisco: Holden-Day.

Jaber, J. J., Ismail, N., Wadi, S. A., \& Saleh, M. H. (2017). Forecasting of volatility risk for Jordanian banking sector. Far East Journal of Mathematical Sciences, 101(7), 1491-1507.

Javier, C., Rosario, E., Francisco, J. N., \& Antonio, J. C. (2003). ARIMA models to predict next electricity price. IEEE Transactions on Power Systems, 18(3), 1014-1020.

Khashei, M., Bijari, M., \& Ardali, G. A. R. (2009). Improvement of auto-regressive integrated moving average models using fuzzy logic and artificial neural networks (ANNs). Neurocomputing, 72(4-6), 956-967.

Khashel, M., Bijari, M., \& Ardali, G. A. R. (2012). Hybridization of autoregressive integrated moving average 
(ARIMA) with probabilistic neural networks (PNNs). Computers \& Industrial Engineering, 63(1), 37-45.

Lee, C., \& Ho, C. (2011). Short-term load forecasting using lifting scheme and ARIMA model. Expert System with Applications, 38(5), 5902-5911.

Meyler, A., Kenny, G., \& Quinn, T. (1998). Forecasting Irish inflation using ARIMA models. Central Bank of Ireland Research Department, Technical Paper, 3/RT/1998.

Mitra, S. K. (2009). Optimal combination of trading rules using neural networks. International Business Research, 2(1), 86-99.

Pai, P. F., \& Lin, C. S. (2005). A hybrid ARIMA and support vector machines model in stock price forecasting. Omega, 33(6), 497-505.

Vaccaro, A., El-Fouly, T. H. M., Cañizares, C. A., \& Bhattacharya, K. (2015, June). Local learning-ARIMA adaptive hybrid architecture for hourly electricity price forecasting. In Power Tech, 2015 IEEE Eindhoven (pp. 1-6). IEEE.

Wang, C. (2011). A comparison study of between fuzzy time series model and ARIMA model for forecasting Taiwan Export. Expert System with Applications, 38(8), 9296-9304.

Wang, J. J., Wang, J. Z., Zhang Z. G., \& Guo, S. P. (2012). Stock index forecasting based on a hybrid model. Omega, 40, 758-766.

Wei, L. Y. (2013). A hybrid model based on ANFIS and adaptive expectation genetic algorithm to forecast TAIEX. Economic Modelling, 33, 893-899.

Yunus, K., Thiringer, T., \& Chen, P. (2016). ARIMA-based frequency-decomposed modeling of wind speed time series. IEEE Transactions on Power Systems, 31(4), 2546-2556.

\section{Copyrights}

Copyright for this article is retained by the author(s), with first publication rights granted to the journal.

This is an open-access article distributed under the terms and conditions of the Creative Commons Attribution license (http://creativecommons.org/licenses/by/4.0/). 